\title{
Expression and localization of the progesterone receptor in mouse and human reproductive organs
}

\author{
Stefan Cuoni Teilmann, Christian Alexandro Clement ${ }^{2}$, Jørgen Thorup ${ }^{1}$, Anne Grete Byskov \\ and Søren Tvorup Christensen ${ }^{2}$ \\ Laboratory of Reproductive Biology, Juliane Marie Center, Rigshospitalet, Copenhagen, Denmark \\ ${ }^{1}$ Department of Paediatric Surgery, Section 4072, Rigshospitalet, Copenhagen, Denmark \\ ${ }^{2}$ Department of Biochemistry, Institute of Molecular Biology and Physiology, University of Copenhagen, The August Krogh Building, Universitetsparken 13, \\ DK-2100 Copenhagen, Denmark \\ (Requests for offprints should be addressed to S T Christensen; Email: stchristensen@aki.ku.dk)
}

\begin{abstract}
The effects of gonadotropins on progesterone receptor (PR) expression and localization in the mouse oviduct, uterus, and ovary was examined. In the oviduct ciliated epithelial cells of adult mice and human revealed a unique PR localization to the lower half of the motile cilia whereas the nuclei were unstained or faintly stained. Pubertal female mice were further studied by confocal laser scanning microscopy and western blotting before and after injection with FSH and $\mathrm{LH}$ followed by human chorionic gonadotropin (hCG) injection after a 48 -h period. PR immunolocalization to the oviduct cilia was greatly increased in pubertal mice upon hCG stimulation. In neighboring goblet cells, the PR staining was confined to the nuclei. Nuclear PR localization was evident in epithelial cells of the uterus as well as in a fraction of stromal and muscle cells. Staining intensity and number of stained cells was not affected by hormone stimulation. In the ovary, weak PR immunolocalization was observed in unprimed
\end{abstract}

animals but increased significantly after hCG stimulation. In granulosa cells of preovulatory follicles PR was exclusively observed in mural cells, whereas cumulus cells remained negative. At all stages examined, primary granulosa cell cilia lacked PR staining. SDS-PAGE and western blotting analysis of tissues from oviduct, uterus, and ovary confirmed antibody specificity, and identified two bands corresponding to the PR isoforms PR-A and PR-B. Upon hCG stimulation, a new band cross-reacting with anti-PR emerged above the PR-A form in oviduct fractions, suggesting LH-induced phosphorylation of PR-A. We suggest that ciliary PR in the oviduct plays a role in progesterone signaling after ovulation, possibly via non-genomic events. These novel findings warrant further studies of oviduct and postovulatory signaling events and suggest a sensory role for oviduct cilia in the process of oocyte transport/fertilization.

Journal of Endocrinology (2006) 191, 525-535

\section{Introduction}

Many reproductive functions in mammals are regulated by the ovarian steroids estradiol and progesterone $(\mathrm{P})$. $\mathrm{P}$ is an important local regulator of critical reproductive events such as ovulation, luteinization, gamete transport within the oviduct, and implantation. $\mathrm{P}$ mediates various effects in the female reproductive organs through its cognate nuclear receptors, PR-A and PR-B, which often are co-expressed within the same cells, e.g., in granulosa cells of preovulatory follicles (Hild-Petito et al. 1988, Sheridan et al. 1989, Park \& Mayo 1991, Gava et al. 2004). Both the PR forms are ligand-activated transcription factors that upon ligand binding undergo phosphorylational and conformational changes (Weigel 1996, Clemm et al. 2000). The importance of the two PR isoforms has been demonstrated in PR null mice (PRKO), which are anovulatory and unable to properly respond to exogenous gonadotropins (Lydon et al. 1995). Mice deficient in either PR-A (PRAKO) or PR-B
(PRBKO) have different phenotypes, demonstrating a complex and tissue-specific interplay between the two receptor forms. In PRAKO mice, ovulation is severely hindered and implantation impossible showing that only PR-A is obligatory for mouse female fertility (Mulac-Jericevic et al. 2000).

Cyclic changes of $\mathrm{P}$ and estradiol control homeostasis of the oviduct epithelium as well as formation and beat frequency of the cilia (Brenner 1969, Wessel et al. 2004), although little is known about the underlying regulatory mechanisms. Present research has positioned cilia as key sensory organelles in human health and reproduction (Satir \& Christensen 2006), and increasing evidence suggests a role for sensing cilia in the female reproductive organs. We have previously described the unique localization of signal components to both motile cilia of the oviduct and to primary cilia of ovarian and extraovarian tissues of the mouse, and signaling through these cilia were suggested to play a role in follicular maturation, ovulation, and gamete transport. In the ovary, 
the $\mathrm{Ca}^{2+}$-selective transient receptor potential (TRP) ion channels localize to primary cilia of granulosa cells of antral follicles and to motile cilia of the oviduct (Teilmann et al. 2005). In addition, receptor tyrosine kinases, angiopoetin receptors, localize to cell type-specific primary cilia of the reproductive organs and to the tip of motile cilia in the oviduct (Teilmann \& Christensen 2005).

In the present study, we analyzed murine PR in oviduct, uterus, and ovary by immunolocalization and western blotting techniques upon follicle stimulating hormone (FSH) and human chorionic gonadotropin (hCG) stimulation. Using specific antibodies against PR, we were able to show that hCG radically upregulates PR in nuclei and cytosol of mural granulosa cells of the preovulatory follicles and in motile cilia of the oviduct. These results indicate the discovery of a novel function of PR in reproductive biology, in which ciliary beat frequency may be regulated directly by progesterone via ciliary receptors.

\section{Materials and Methods}

\section{Animals and tissues}

Pubertal female C57Bl/6J mice (21-23 days old, 14 g) were injected intraperitoneally with $30 \mathrm{IU}$ gonadotropins (Menopur: $15 \mathrm{IU}$ FSH and $15 \mathrm{IU}$ luteinizing hormone (LH) (Ferring Pharmaceuticals, Copenhagen, Denmark) followed by 5 IU menotropin (hCG) (Pregnyl, Organon AS, Skovlunde, Denmark) injection $48 \mathrm{~h}$ later. Mice were killed by cervical dislocation $48 \mathrm{~h}$ after FSH or $6 \mathrm{~h}$ after hCG. Non-stimulated mice of coeval age served as controls. Oviducts, uteri, and ovaries were immediately removed and processed for immunohistochemistry (IHC) or western blot and SDS-PAGE analysis. Furthermore, lung, heart, and reproductive organs of 3-month-old female mice in estrous were used as control tissues. Ovaries from three 30-days-old Wistar rats were collected in PBS rinsed from fat and extraovarian tissue, fixed in $4 \%$ para formaldehyde, and processed for IHC. Animal experiments were conducted in accordance with EU guidelines and approved by the Danish Ministry of Justice, Animal Ethics Committee no. 2003/561-713 (A G B).

\section{Human material}

Human material was used after ethical approval was obtained by the ethics committee for Copenhagen and Frederiksberg no. KF 01-170/99, and after informed consent was obtained from each patient following the guidelines in the Declaration of Helsinki.

\section{Immunohistochemistry}

After fixation, oviduct, uterus, and ovary were embedded in paraffin and cut in $8 \mu \mathrm{m}$ thick sections that were collected on microscope slides (SuperFrost/Plus, Menzel Gläser, Germany). Importantly, we found what appeared to be time- and temperature-dependent degradation of specific PR epitopes in the tissue sections examined, leading to decreased or absent staining intensity. Multiple sections from ovaries from three different animals in each group were therefore always stored at $4{ }^{\circ} \mathrm{C}$ and used within a week after cutting. Sections were deparaffinized, rehydrated, and rinsed in PBS. For antigen retrieval, slides were boiled in citric acid buffer $(0.01 \mathrm{M}, \mathrm{pH} 6)$, and incubated for $15 \mathrm{~min}$ in PBS (pH 6.5) containing 5\% (w/v) BSA and $1 \%(\mathrm{v} / \mathrm{v})$ preimmune goat serum (Dako, Glostrup, Denmark). Sections were incubated with one of the following primary antibodies diluted in PBS containing $5 \%(\mathrm{w} / \mathrm{v}) \mathrm{BSA}$ and $0 \cdot 02 \%(\mathrm{w} / \mathrm{v}) \mathrm{NaN}_{3}$ overnight at $4{ }^{\circ} \mathrm{C}$ : diagnostic grade rabbit monoclonal PR antibody (1:300, Clone SP2, LabVision, Westinghouse Drive, Fremont, CA, USA) directed against an epitope corresponding to amino acid (aa) sequence 410-516 in mouse PR and to aa sequence 412-526 in human PR was a gift from AH Diagnostics, Aarhus, Denmark. Mouse monoclonal PR antibody (1:300, Clone Ab-4, NeoMarkers, LabVision) directed against the N-terminal region of PR, i.e. aa sequence $1-557$ in mouse PR and aa sequence 1-566 in human PR. Mouse monoclonal anti-acetylated $\alpha$-tubulin (1:3000, Cat no. T6793, Sigma-Aldrich) for localization of cilia and cytosolic network of acetylated microtubules (Alieva et al. 1999). Non-specific binding of the PR antibody was evaluated by substitution with preimmune rabbit IgG (Dako) with the same concentration as primary antibody. Primary antibodies were detected by 1 -h incubation at room temperature with species-specific Alexa Fluor anti-IgG $\mathrm{F}\left(\mathrm{ab}^{\prime}\right)_{2}$ secondary antibody $(5 \mu \mathrm{g} / \mathrm{ml}$, Molecular Probes, Eugene, OR, USA) and counterstained with propidium iodide $(1 \mu \mathrm{g} / \mathrm{ml})$ or TO-PRO-3 iodide $(2 \mu \mathrm{g} / \mathrm{ml}$ Molecular Probes) in PBS for $8 \mathrm{~min}$. After washing, slides were mounted in 1:1 (v/v) glycerol/ PBS with $2 \%(\mathrm{w} / \mathrm{v}) \mathrm{NaN}_{3}$ and sealed with nail polish. A series of sections as well as isolated and fixed single cell preparations (see below) were double labeled with anti-acetylated $\alpha$-tubulin and anti-PR.

\section{Tissue and immunofluorescence analysis}

The three parts of the oviduct studied were divided into the following separate groups: fimbriae (the cranial part), ampulla (the middle part), and isthmus (the caudal part). For single cell analysis, the cranical and middle part of the oviduct were collected in PBS with $\mathrm{Ca}^{2+} / \mathrm{Mg}^{2+}$ and cut into small pieces to expose the ciliated epithelium. Then the tissues were placed in ice-cold incubation buffer containing $0 \cdot 25 \mathrm{M}$ sucrose, $0 \cdot 02 \mathrm{M}$ HEPES, $2 \mathrm{mM}$ EDTA, and $25 \mathrm{mM} \mathrm{KCl}$ supplemented with freshly made phenylmethylsulfonyl fluoride $(1 \mathrm{mM})$ and $\mathrm{N}$-ethylmaleimide $(10 \mathrm{mM})$. For the next $50 \mathrm{~min}$, the sample was kept on ice and vortexed intermittently. Pieces of oviduct were removed and an equal volume of incubation buffer was added. After $60 \mathrm{~s}$ of incubation, the material was vortexed and spun down $(500 \mathrm{~g}$ for $10 \mathrm{~min}$ ). The pellet (containing ciliated cortices, single cells and nuclei) was fixed and loaded onto glass cover slips for immunohistochemical analysis. Ovarian follicles were categorized according to Pedersen \& Peters (1968) and antral follicles were classified as atretic when $>5$ granulosa cells 
were pyknotic, corresponding to the stage one atresia described (Byskov 1974) and was excluded from analysis. Stained sections and isolated cells were observed on an IX70 confocal laser scanning microscope (Olympus, Tokyo) with a Krypton/Argon laser using a $60 \times$ oil immersion objective (NA:1-25) and a $40 \times$ air objective (NA:0·85), both equipped with appropriate Normarski optics. Care was taken to avoid bleedthrough between channels, and at the beginning of each evaluation, image settings was optimized so that it contained the maximum number of gray levels, and during subsequent image acquisition all settings (laser power, photomultiplier tube gain and offset) were kept constant so that the images could be compared.

\section{SDS-PAGE and western blot analysis}

In the isolation of oviduct infundibulum samples, care was taken only to include the outer cranial part in order to minimize nonciliated epithelium from the sample. Ovaries and oviducts were cleaned from fat and connective tissues before protein isolation. Protein was extracted using a common protocol (VanSlyke \& Musil 2001). The protein concentrations were estimated using a BCA protein kit (Pierce Biotechnology, Rockford, IL, USA), and proteins were resolved by gel electrophoresis under denaturing and reducing conditions and electrophoretically transferred to nitrocellulose membranes as previously described (Christensen et al. 2001). The membranes were incubated with anti-PR (1:300) and anti- $\beta$-tubulin (1:300; Cat no. T4026, Sigma-Aldrich) and antibody cross-reactivities were identified with species-specific alkaline phosphatase-coupled secondary antibodies (1:1200, Jackson Laboratory, Bar Harbor, ME, USA) followed by developing with 5-bromo-4-chloro-3-indolyl phosphate/nitro blue tetrazolium (BCIP/NBT) (KPL, Cessna Court, Gaithersburg, Maryland, USA).

\section{Statistical analysis}

Band intensities of PR proteins in western blot analysis were measured using UN-SCAN-IT Version 5.1 (Silk Scientific, Inc., Orem, Utah, USA). Data are presented as mean values \pm S.E.M. from a minimum of three individual experiments, in which tissue homogenates were obtained from a minimum of six animals. Significant differences in the level of PR expression between non-stimulated and hormone-stimulated mice were estimated using a two-tailed paired $t$-test. For all statistical evaluations, $P$ values $<0.05,<0.01$, and $<0.001$ were considered statistically significant, very significant, and extremely significant respectively.

\section{Results}

Localization and expression of PR in the ovary upon hormone stimulation of pubertal mice

In the untreated pubertal ovary anti-PR (SP2) weakly localized to theca and granulosa cells (Fig. 1A and D), and a slight nuclear anti-PR (SP2) staining was observed in the interstitial tissue. Forty-eight hours after FSH a subpopulation of theca cells around large antral follicles (stage 6) began to show nuclear PR immunoreactivity (SP2), whereas the PR signal seemed reduced in a subpopulation of granulosa cells of any follicle stage (Fig. 1B and E). Six hours after hCG, nuclei of many theca cells in the large preovulatory follicles (stage 7) were anti-PR (SP2) positive (Fig. 1C). At this stage, follicular granulosa cells are divided into two distinct populations: mural granulosa cells facing the theca cell layer and cumulus granulosa cells facing the oocyte. Clearly, hCG stimulation dramatically increased the level of anti-PR (SP2) immunofluorescence of mural granulosa cells, whereas cumulus cells remained $\mathrm{PR}$ negative (Fig. 1F). To further characterize PR localization in the granulosa cells of hCG-stimulated ovaries, we used anti-acetylated $\boldsymbol{\alpha}$-tubulin to detect primary cilia in mural and cumulus granulosa cells in stage 7 follicles. Most non-dividing mural and cumulus granulosa cells had a primary cilium that was often presented into the antrum (Fig. 1G). In double labelings of anti-acetylated $\boldsymbol{\alpha}$-tubulin and anti-PR in granulosa cells, nuclear and cytosolic PR expression did not correlate with the presence of a cilium and no detectable co-localization between acetylated $\boldsymbol{\alpha}$-tubulin and PR was observed (Fig. 1G). As a further control on PR localization in the ovary, tissue sections of mice were subjected to co-localization analysis with anti-PR (clone $\mathrm{Ab}-4)$ that recognizes the entire $\mathrm{N}$-terminal region of $\mathrm{PR}$ (Fig. $1 \mathrm{H})$. It is seen that SP2 and Ab-4 co-localize to mural granulosa cells in hCG-stimulated ovaries, confirming specific immunoreactivity to PR in this cell population.

A strong immunofluorescent signal in the cytoplasm of mouse oocytes from all follicle stages including atresia was observed with Anti-PR (SP2; Fig. 1A-F). However, no immunofluorescent signal was detected with this antibody in oocytes from either rat or human (Fig. 1I). Importantly, the Ab4 antibody did not label oocytes from either rat or mouse (Fig. 1I). Since, unspecific immunohistochemical staining of oocytes is a well known problem, these observations suggest that excessive oocyte staining can be considered a phenomenon restricted to that particular antibody when used on mouse tissue. Although we do not know whether this signal represents a true receptor population within the oocytes, it is most likely an artifact and has not been investigated further.

Using western blot analysis anti-PR (SP2) specifically recognized two $\mathrm{PR}$ forms of approximately 115 and $83 \mathrm{kDa}$, corresponding to the $\mathrm{B}$ - and $\mathrm{A}$-form respectively. In the ovary protein fraction of the non-stimulated mice both PR forms could be detected at a low level (Fig. 1J). After $48 \mathrm{~h}$ with FSH, the level of PR-A was significantly reduced to about $40 \%$ compared with that of the non-stimulated mice (Fig. 1J and K). In contrast, $6 \mathrm{~h}$ after hCG, PR-A and PR-B were present at a level about 19- and 8-fold higher than in the non-stimulated mice respectively (Fig. 1J and L). In some experiments, we also observed a protein migrating in SDS-PAGE as a $60 \mathrm{kDa}$ protein, which was recognized by anti-PR (SP2) and upregulated upon hCG stimulation (data not shown). 

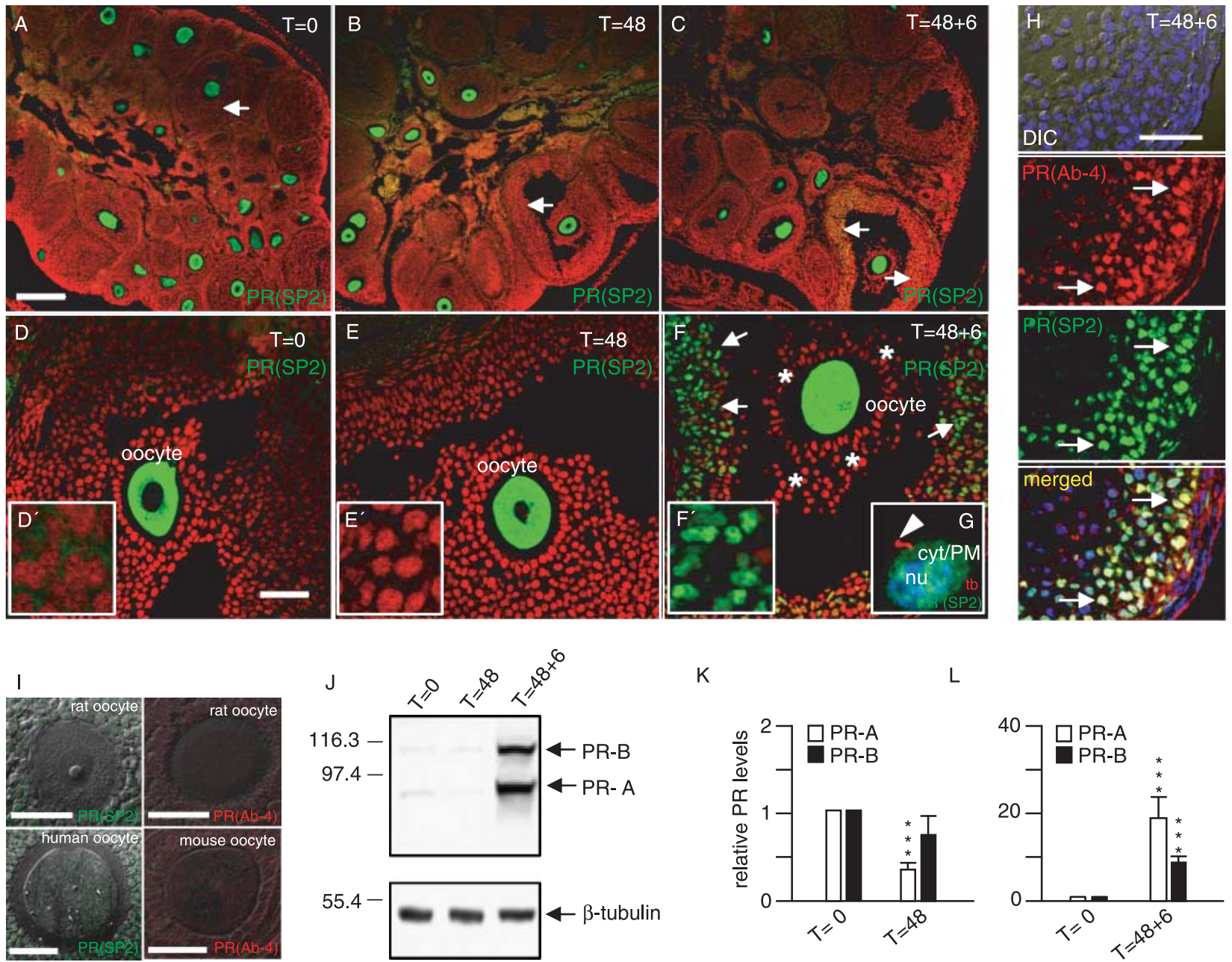

K

$\mathrm{L}$

Figure $1 \mathrm{Imm}$ Imolocalization of progesterone receptor in ovary tissue sections before and after gonadotropic stimulation of pubertal female $\mathrm{C} 57 \mathrm{Bl} / 6 \mathrm{~J}$ mice. (A) Control ovary (no stimulation; $T=0$ ). (B) Forty-eight hours after FSH stimulation $(T=48)$. (C) Six hours after additional stimulation with hCG $(T=48+6)$. Scale bar $(\mathrm{A}-\mathrm{C}): 200 \mu \mathrm{m}$. Corresponding close ups of pubertal $(T=0)$ stage $5 \mathrm{~b}$ follicle and granulosa cells $\left(\mathrm{D}\right.$ and $\mathrm{D}^{\prime}$ ), stage 6 follicle and granulosa cells after $48 \mathrm{~h} \mathrm{FSH/LH}(T=48)$ ( $\mathrm{E}$ and $\mathrm{E}^{\prime}$ ), and stage 7 follicle and cumulus granulosa cells (arrows) $6 \mathrm{~h}$ after hCG $(T=48+6)\left(\mathrm{F}\right.$ and $\left.\mathrm{F}^{\prime}\right)$. Cumulus granulosa cells are marked with asterisks. Nuclei are detected with propidium iodide (red). Scale bar (D-F): $50 \mu \mathrm{m}$. (G) Single mural granulosa cell presenting a primary cilium detected with anti-acetylated $\alpha$-tubulin (red, arrow head). Nuclei are detected with TO-PRO (blue). nu, nucleus; cyt, cytoplasm; PM, plasma membrane. Progesterone receptor is localized with monoclonal rabbit anti-PR (SP2; green). (H) Co-immunolocalization of progesterone receptor with monoclonal rabbit anti-PR (SP2; green) and monoclonal mouse anti-PR (Ab-4; red) in mural granulosa cells (arrows) of a stage 7 follicle and 6 h after hCG $(T=48+6)$. Nuclei are detected with TO-PRO (blue). Scale bar: $50 \mu \mathrm{m}$ (I) Immunolocalization of anti-PR (SP2; green) and anti-PR (Ab-4; red) in tissue sections of adult rat, human, and mouse ovaries. Scale bar: $50 \mu \mathrm{m}$. (J). SDS-PAGE and western blot analysis with anti-PR (SP2) showing the expression of progesterone receptor forms, PR-A (ca. $83 \mathrm{kDa}$ ) and PR-B (ca. $115 \mathrm{kDa}$ ), at different times after the gonadotropic stimulation. Anti- $\beta$-tubulin was used as a loading control. Molecular markers (kDa) are shown to the left. ( $\mathrm{K}$ and $\mathrm{L}$ ) Relative levels of PR-A (open bars) and PR-B (solid bars) in ovaries after $48 \mathrm{~h} \mathrm{FSH}(T=48$ ) and $6 \mathrm{~h} \mathrm{hCG}(T=48+6)$ compared with pubertal controls $(T=0)$. Error bars indicate standard errors from five separate experiments. Significant changes in PR levels are marked with one, two and three asterisks, for $P<0 \cdot 05, P<0 \cdot 01$, and $P<0 \cdot 001$ respectively.

\section{Localization of PR in the oviduct and uterus of adult mice}

Localization and expression of PR isoforms in the oviduct and uterus were initially examined in tissues of adult mice (Fig. 2). In all parts of the oviduct, nuclear PR immunoreactivity was detected in a fraction of the stromal cells and the luminal non-ciliated epithelial cells. In ciliated epithelial cells, anti-PR (SP2) uniquely localized to the cilia, whereas the antibody exclusively localized to the nucleus in non-ciliated glandular goblet epithelial cells (Fig. 2A). In the uterus, anti-PR (SP2) localized to nuclei of epithelial, stromal, and muscle cells (Fig. 2B). In the stroma and muscle layers, PR staining had a mosaic-like pattern with 

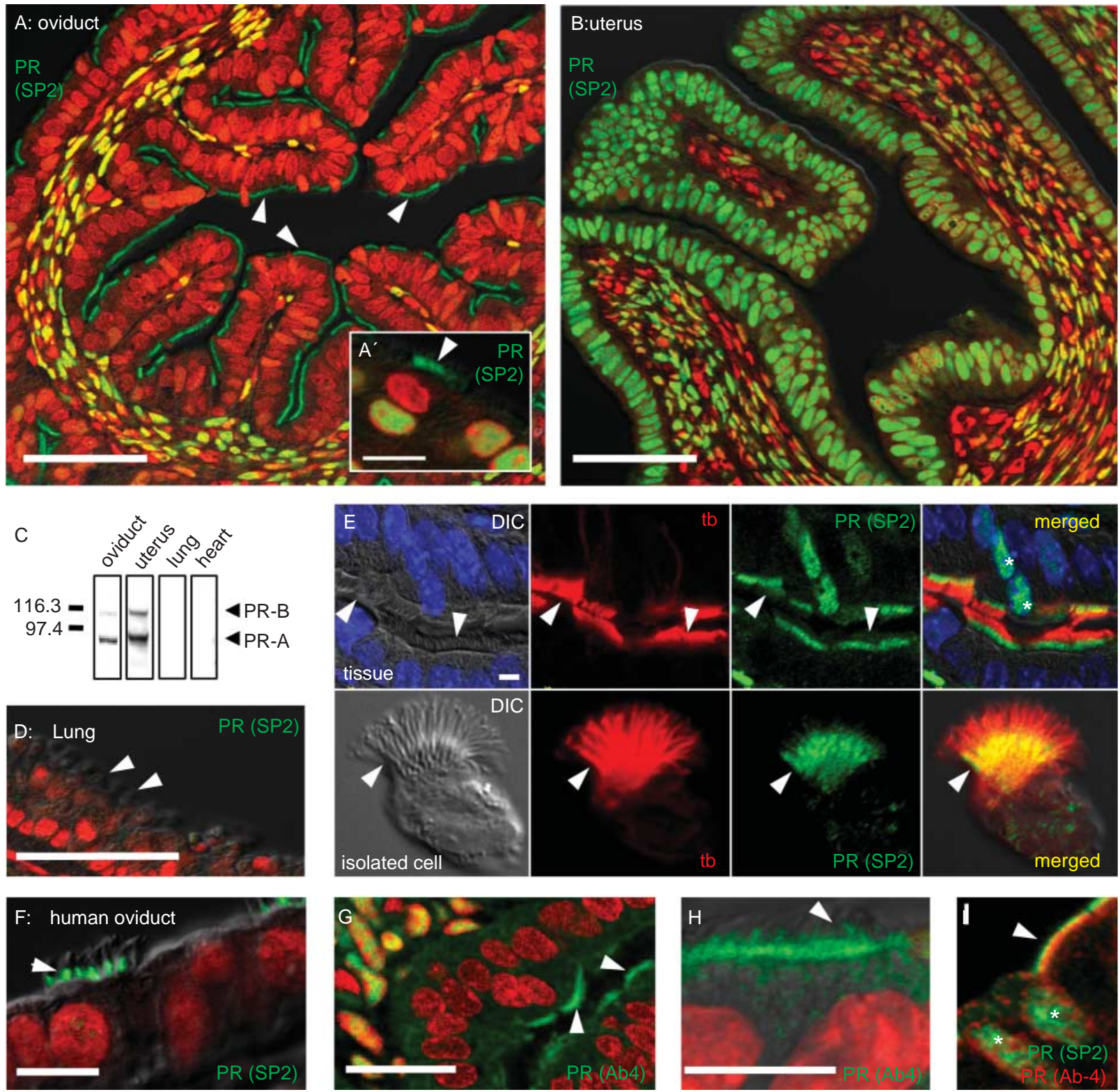

Figure 2 Immunolocalization of progesterone receptor in tissue sections of oviduct (A) and uterus (B) of adult C57Bl/6J female mice. Cilia are marked with arrow heads and nuclei are stained with propidium iodide (red). Progesterone receptor is localized with monoclonal rabbit anti-PR (SP2; green). Scale bars: $50 \mu \mathrm{m}$. (A') Close up of the mouse oviduct epithelium showing ciliated and goblet cells. Cilia are marked with arrow heads. Nuclei are stained with propidium iodide (red) and progesterone receptor is localized with monoclonal rabbit anti-PR (SP2; green). Scale bar: $10 \mu \mathrm{m}$. (C) SDS-PAGE and western blot analysis with anti-PR (SP2) showing the expression of progesterone receptor forms, PR-A (ca. $83 \mathrm{kDa}$ ) and PR-B (ca. $115 \mathrm{kDa}$ ) in extracts of oviduct, uterus, lung, and heart of adult mice. Molecular markers ( $\mathrm{kDa}$ ) are shown to the left. (D) Immunolocalization of anti-PR (SP2) in a tissue section of ciliated lung epithelium from mouse (arrow heads indicate cilia). Nuclei are stained with propidium iodide (red). Scale bar: $50 \mu \mathrm{m}$. (E) Ciliary immunolocalization of anti-PR (SP2; green) in the mouse oviduct in a tissue section (upper row; scale bar: $5 \mu \mathrm{m}$ ) and in an isolated ciliated epithelial cell (lower row; scale bar: $1 \mu \mathrm{m}$ ). Cilia are detected with anti-acetylated $\alpha$-tubulin (red) and marked with arrow heads. Nuclei are detected with TO-PRO (blue). Nuclear localization of anti-PR is indicated with asterisks. (F) Immunolocalization of anti-PR (SP2; green) in a tissue section of ciliated epithelial cells from adult human oviduct (arrow heads indicate cilia). Nuclei are stained with propidium iodide (red). Scale bar: $5 \mu \mathrm{m}$. ( $\mathrm{G}$ and $\mathrm{H}$ ) Immunolocalization of anti-PR (Ab-4; green) in tissue sections of ciliated epithelial cells from adult mouse (arrow heads indicate cilia). Nuclei are stained with propidium iodide (red). Scale bars: $25 \mu \mathrm{m}(\mathrm{G})$ and $5 \mu \mathrm{m}(\mathrm{H})$. (I) Co-immunolocalization of anti-PR (Ab-4; red) and anti-Pr (SP2; green) in a tissue section of ciliated epithelial cells from adult mouse (arrow heads indicate cilia). Nuclei are stained with propidium iodide (red) and nuclear localization of anti-PR is indicated with asterisks. 
neighboring cells having PR-positive or negative nuclei. SDS-PAGE and western blot analysis showed that anti-PR (SP2) recognized $\mathrm{PR}-\mathrm{A}$ and $\mathrm{PR}-\mathrm{B}$ isoforms in isolated tissues of both oviduct and uterus (Fig. 2C). PR expression was not detected in lung extracts (Fig. 2C) and no PR immunoreactivity was detected in lung cilia and epithelial cells (Fig. 2D). This confirms specificity of PR to cilia of the oviduct. Further, PR was not detected in heart extracts (Fig. 2C).

The subcellular localization and expression level of PR in the oviduct was investigated by high resolution confocal laser scanning microscopy. Double labeling of anti-acetylated $\boldsymbol{\alpha}$-tubulin and anti-PR (SP2) in tissue sections and isolated cells from the oviduct epithelium of hCG-stimulated mice showed that PR was confined to the lower region of the cilia and confirmed that nuclear PR is mostly limited to goblet cells in the epithelium (Fig. 2E). A similar pattern of immunolocalization was observed in human oviduct epithelium (Fig. 2F). As a further control, PR localization in the mouse oviduct was investigated using anti-PR (clone Ab-4) raised against the entire $\mathrm{N}$-terminal region of $\mathrm{PR}$. This antibody localized in a similar fashion as SP2, i.e. it localized to the nuclei of stromal cells, to the nuclei of goblet cells, and to the lower part and at the base of the cilia in ciliated epithelial cells (Fig. 1G-I). Importantly, we observed that

A
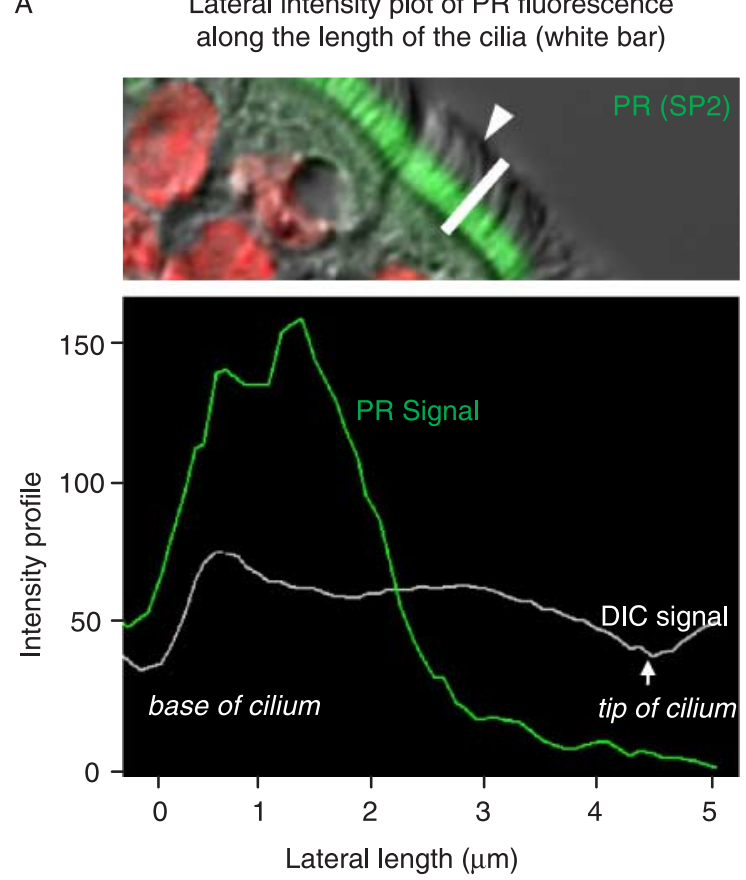

tissue sections kept at room temperature for several days show no or very little ciliary PR localization, whereas localization to nuclei remains intact. This may mean that ciliary $P R$ is subjected to rapid degradation if sections are not stored properly.

In order to analyze ciliary localization of PR in more detail, we performed a lateral inspection of anti-PR (SP2) fluorescence along the length of the cilia in tissue sections of oviduct epithelial cells in hCG-stimulated mice. We used the differential interference contrast (DIC) signal as well as a vertical intensity plot of PR fluorescence and acetylated $\boldsymbol{\alpha}$-tubulin fluorescence that mark individual cilia along the surface of the cells (Fig. 3). The lateral inspection showed that PR localization was restricted to the lower half of the ciliary area (Fig. 3A), and that this localization was specifically assigned to individual cilia (Fig. 3B). These results show that PR in ciliated epithelial cells localizes to the lower half of the cilia and not to microvilli, which are positioned at the base between individual cilia.

Localization and expression of PR in the oviduct and uterus upon hormone stimulation of pubertal mice

In the untreated pubertal oviduct, PR (SP2) predominantly localized to stromal cell nuclei, whereas ciliary localization

B

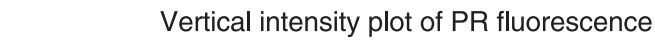
along the cell surface (white bar)
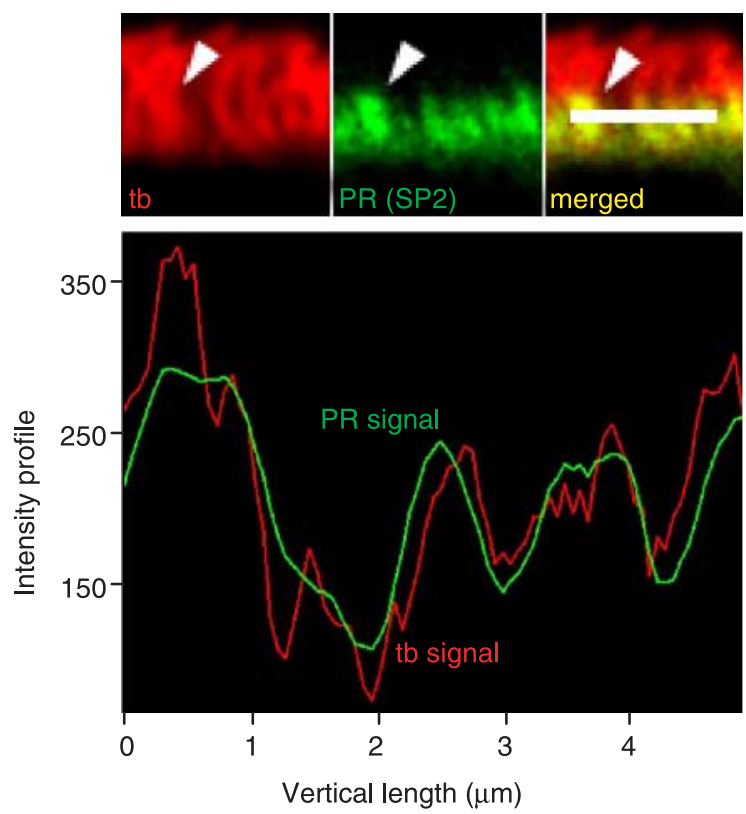

Figure 3 Subciliary immunolocalization of progesterone receptor (green) in tissue sections of oviduct of adult C57Bl/6J female mice. (A) Lateral fluorescence intensity profile of PR immunofluorescence (SP2) along the length of the cilia of the infundibulum (white bar). DIC profile was used to define the base and the tip of the cilium. (B) Vertical fluorescence intensity profile of PR immunofluorescence (SP2) along the cell surface (white bar). Anti-acetylated $\alpha$-tubulin (red) was used to define the cilia (arrow heads) along the epithelial surface. 
was weak (Fig. 4A). Upon 48 h FSH stimulation nuclear PR immunoreactivity was increased in the stromal cell nuclei of the ampulla and isthmus, whereas this was less pronounced in stromal cells of the infundibulum (not shown). Six hours after hCG, the stromal as well as the non-ciliated epithelial cell nuclei PR immunoexpression was increased in all regions of the oviduct with the weakest relative staining intensity observed in the infundibulum (Fig. 4B). At this time, ciliary PR localization was heavily increased along the entire oviduct; this was also associated with a minor nuclear PR staining in the ciliated epithelial cells of the ampulla (Fig. 4B). The increase in ciliary $\mathrm{PR}$ along the oviduct was predominantly confined to the lower half of the cilia (Fig. 4C). Upon elicitation of ovulation $16 \mathrm{~h}$ after hCG treatment, PR was still absent in mural granulosa cells but present at a high level in the cilia of the oviduct (Fig. 4D). The figure shows a close up of the cumulus cells in close proximity with the cilia of the oviduct. These results support the conclusion that ciliary PR is important during transport of the cumulusoocyte complex, since cumulus cells secrete progesterone to the oviductal fluid.

In protein samples from whole infundibulum tissue, PR-A and PR-B immunoreactivity could be demonstrated with antiPR (SP2) in western blot analysis in both non-stimulated and hormone-stimulated mice (Fig. 4E). However, the level of these proteins increased significantly upon hormonal stimulation, such that the levels of PR-A and PR-B increased about twofold after $48 \mathrm{~h}$ of FSH stimulation, and three- and fourfold respectively after an additional $6 \mathrm{~h}$ treatment of hCG (Fig. 4E and F). Further, after $6 \mathrm{~h}$ of hCG, we observed the appearance of a distinct and major PR-immunoreactive protein band migrating just above PR-A (Fig. 4E). The level of this band was increased about 25-fold upon hCG treatment (Fig. 4F). It was also observed that the increase in the level of PR-B upon hormonal stimulation was associated with a slight migration shift such that the protein migrated at a higher molecular mass (Fig. 4E).

In the uterus, the luminal epithelium PR localization was less intense after $48 \mathrm{~h}$ of FSH, although after $6 \mathrm{~h}$ of hCG, the nuclear epithelial cell staining slightly intensified (data not shown). Uterus stroma and muscle cell nuclei PR staining was comparable in all groups examined. Western blot analysis of protein samples from uterus indicated that the levels of PR-A and PR-B are not significantly altered upon hormonal stimulation (Fig. $4 \mathrm{H}$ and $\mathrm{G}$ ), although the PR-A protein band appeared slightly more diffuse after hCG.

\section{Discussion}

In the mouse oviduct, we show here for the first time a unique PR localization to motile cilia of the epithelial cells. The biological significance of this finding is strengthened by the fact that the PR staining intensity increased upon gonadotropic stimulation of pubertal mice. The gonadotropin-primed mouse has close similarities with the preovulatory cyclic mouse and the staining pattern of PR in the fallopian tube, ovary, and uterus in the present study is largely comparable (Gava et al. 2004). However, previous studies failed to identify PR in ciliated cells of the oviduct and it was speculated that effects on ciliary activity were mediated by goblet or stroma cells positive for PR (Okada et al. 2003). Our findings on ciliary PR suggest a novel function of PR that could aid in the regulation of ciliary activity and function of oviduct epithelium.

The observed PR localization is confined to the lower half and at the base of the cilium, suggesting that ciliary activity regulated by $\mathrm{P}$ is mediated through effector molecules that specifically localize to this part of the cilium. Fliegauf et al. (2005) showed that outer arm dynein (OAD) heavy chains regulating ciliary beat frequency in human respiratory cilia and sperm flagella may be regionally and differentially distributed along the axoneme, indicating that regulated beat frequency is controlled by regional localization of OAD heavy chains. Controlled ciliary beating is essential for proper pickup and transport of the ovulated cumulus-oocyte complex (COC), although the identity of extracellular signals that regulate beat frequency and form are not clear. It has been shown that estrogen accelerates and $\mathrm{P}$ decelerates oviduct egg transport (Mahmood et al. 1998, Orihuela \& Croxatto 2001, Orihuela et al. 2001) and antiprogestins added to natural cyclic rats accelerates ovum transport and results in premature arrival to the uterus (Fuentealba et al. 1987). More recently, Wessel et al. (2004) used explants of bovine oviduct to show that $\mathrm{P}$ regulates ciliary beat frequency by a fast, non-genomic hormonal interaction. Ciliary beat frequency in the different parts of the oviduct is regulated by $\mathrm{Ca}^{2+}$ (Verdugo 1980), and ciliary beat frequency changes during the natural cycle and during pregnancy (Lyons et al. 2002). We suggest that ciliary PR directly modulates the ciliated oviduct epithelium by operating as a fast means to sense and relay changes in the levels of $\mathrm{P}$ in the oviduct, such as those induced through release of follicular fluid at ovulation or released by COCs. Cumulus cells from ovulated COCs are known to produce and secrete large amounts of P (Vanderhyden \& Macdonald 1998), and thus we speculate that these signaling pathways involve specific $\mathrm{Ca}^{2+}$-regulated functions in these cells. Recent studies of the mouse oviduct have shown that the $\mathrm{Ca}^{2+}$-selective TRP ion channel, polycystin-2, and the $\mathrm{Ca}^{2+}$-binding receptor protein, polycystin-1, are highly upregulated in the cilia along the entire oviduct upon hCG stimulation (Teilmann et al. 2005). In addition, the $\mathrm{Ca}^{2+}$ permeable cation channel gated by thermal and osmotic stimuli, TRP vanilloid 4 (TRPV4), localizes to a subpopulation of motile cilia on epithelial cells of the ampulla and isthmus (Teilmann et al. 2005), and the TRPV4 channel was suggested to be involved in the coupling of fluid viscosity changes to oviduct epithelial ciliary activity (Andrade et al. 2005). Together, these findings favor a model where ciliated oviduct epithelial cells perceive signals from the extracellular milieu in a previously unappreciated manner. Thus, ciliary signaling components such as membrane-associated $\mathrm{P}$ receptors and TRP ion channels 

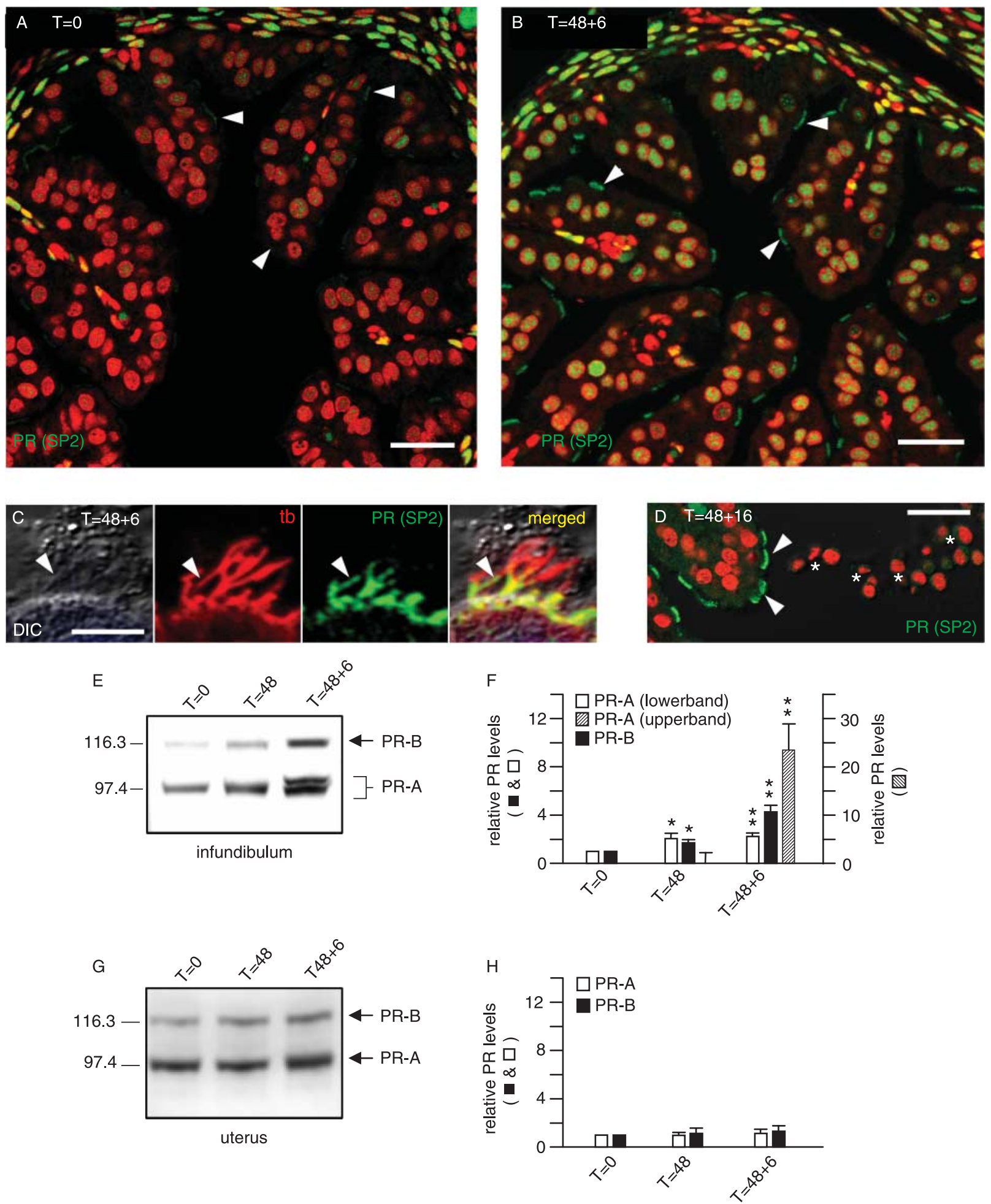
may act in concert to co-ordinate uptake, transport, and fertilization of the gamete.

Western blotting analysis of isolated infundibulum suggests that PR-A is the principal PR form undergoing transcriptional and/or posttranslational changes in this part of the oviduct. Cyclic changes in PR localization in the uterus and oviduct can easily be appreciated by immunohistochemistry during the estrous cycle, but when analyzed by immunoblotting only small changes in total PR expression are observed (Ohta et al. 1993, Gava et al. 2004). Changes in the relative amount and distribution of the two PR isoforms can alter the signaling capacity dramatically and both PR isoforms undergo phosphorylation upon ligand binding that results in increased sensibility to changes in the levels of $\mathrm{P}$ (Lange 2004). Phosphorylation of PR may also facilitate subcellular relocalization (Qiu \& Lange 2003, Lange 2004). We suggest that the PR band observed migrating just above PR-A in SDS-PAGE analysis of oviduct protein fractions, and emerging specifically after hCG stimulation, may represent a phosphorylated and sensitized/activated form of PR-A as described previously (Sheridan et al. 1989, Denner et al. 1990, Poletti et al. 1993, Takimoto \& Horwitz 1993).

We also investigated the expression and localization of PR in the ovary and confirmed previous findings that both nuclear and cytoplasmic PR localization in theca and granulosa cells of large preovulatory follicles greatly increases upon administration of LH (Iwai et al. 1991, Park \& Mayo 1991, Robker et al. 2000, Jo et al. 2002). PR mRNA expression was suggested to be confined to mural granulosa cell compartment (Conneely et al. 2003) and no PR expression was reported in isolated mouse cumulus cells immediately after isolation (Conneely et al. 2001). In agreement with these studies, we find that PR localization in preovulatory follicles is restricted to mural granulosa cells. In our study, luteinizing granulosa cells displayed less staining than non-luteinized granulosa cells $6 \mathrm{~h}$ after hCG. Induction of PR isoforms in granulosa cells upon the preovulatory gonadotropin surge have been reported in bovine (Jo et al. 2002), mouse (Shao et al. 2003, Gava et al. 2004), rat (Park \& Mayo 1991), porcine (Machelon et al. 1996, Slomczynska et al. 2000), and in the primate (Hild-Petito et al. 1988,
Sheridan et al. 1989, Iwai et al. 1990, Suzuki et al. 1994). Although species differences clearly exist, some PR expression in granulosa cells appears to sustain in the corpus luteum. Our western blot analysis of ovary protein fractions supported the immunohistochemical findings in that PR-A and PR-B forms are highly upregulated in ovaries in mice after hCG. Further, we observed a shift in molecular mass for PR-A in western blot analysis of ovary extracts upon hCG treatment, but this shift was less prominent compared with that observed in the oviduct. Most interestingly, the protein level of ovarian PR-A is reduced in mice treated with FSH and prior to stimulation with hCG compared with the non-stimulated mice. To our knowledge, these observations are the first to show a downregulation of ovarian PR specifically upon FSH stimulation, suggesting additional roles of $\mathrm{PR}$ in preovulatory follicle development. The mechanism by which ovarian PR is suppressed by FSH remains to be determined.

It is now clear that $\mathrm{P}$ in many cell types may act via nongenomic pathways (Luconi et al. 2002, Peluso et al. 2003, Wessel et al. 2004) and in non-luteinized granulosa cells $P$ stimulation rapidly increases intracellular levels of $\mathrm{Ca}^{2+}$ via membrane receptors (Machelon et al. 1996). The increased non-nuclear PR localization in granulosa cells of preovulatory follicles could therefore represent membrane-bound PR forms that act through $\mathrm{Ca}^{2+}$ signaling and possibly in coordination with $\mathrm{Ca}^{2+}$ channels (Teilmann et al. 2005) and $\mathrm{Ca}^{2+}$ currents (Asem et al. 2002). In rat ovaries, P was suggested to inhibit granulosa cell apoptosis through the binding and activation of a $60 \mathrm{kDa}$ membrane protein that functions as a low-affinity, high-capacity receptor for $\mathrm{P}$ (Peluso et al. 2001, Peluso 2004). It remains an open question whether the ca. $60 \mathrm{kDa}$ anti-PR immunoreactive protein observed in some western blot analysis of granulosa cells in preovulatory follicles (data not shown) represents a membrane-bound PR form.

In conclusion, PR principally localizes to the lower half and at the base of the cilium in ciliated oviduct epithelium, whereas non-ciliated epithelial cells primarily show nuclear receptor localization. In contrast, ciliated mural granulosa cells uniquely express cytosolic and nuclear PR. Further, cellspecific localization and expression of $\mathrm{PR}$ are highly regulated

Figure 4 Immunolocalization of progesterone receptor with anti-PR (SP2; green) in oviduct tissue sections before and after gonadotropic stimulation of pubertal female C57Bl/6J mice. (A) Control ovary (no stimulation; $T=0$ ); (B) Forty-eight hours after FSH stimulation and $6 \mathrm{~h}$ after additional stimulation with hCG $(T=48+6)$. Cilia are marked with arrow heads and nuclei are detected with propidium iodide (red). Scale bars: $25 \mu \mathrm{m}$. (C) Close up of the ciliated oviduct epithelium of stimulated mice $(T=48+6)$. Cilia are detected with anti-acetylated $\boldsymbol{\alpha}$-tubulin (red, arrow heads) and nuclei were detected with TO-PRO (blue). Scale bar: $5 \mu \mathrm{m}$. (D) Forty-eight hours after FSH stimulation and $16 \mathrm{~h}$ after additional stimulation with $\mathrm{hCG}(T=48+16)$. Cilia are marked with arrow heads, cumulus granulosa cells from ovulated ovary are marked with asterisk and nuclei are detected with propidium iodide (red). Scale bars: $25 \mu \mathrm{m}$. (E) SDS-PAGE and western blot analysis with anti-PR showing the expression of progesterone receptor forms, PR-A (ca. 83 kDa) and PR-B (ca. $115 \mathrm{kDa}$ ), in oviduct before and after gonadotropic stimulation. Molecular markers ( $\mathrm{kDa}$ ) are shown to the left. (F) Relative levels of PR-A lower protein band (open bars), PR-A upper protein band (hatched bars), and PR-B (solid bars) in oviduct after $48 \mathrm{~h}$ FSH $(T=48)$ and $6 \mathrm{~h}$ of hCG $(T=48+6)$ compared with pubertal controls $(T=0)$. (G) SDS-PAGE and western blot analysis with anti-PR showing the expression of progesterone receptor forms, PR-A (ca. $83 \mathrm{kDa}$ ) and PR-B (ca. $115 \mathrm{kDa}$ ), in uterus before and after gonadotropic stimulation. Molecular markers (kDa) are shown to the left. (H) Relative levels of PR-A (open bars) and PR-B (solid bars) protein bands in uterus after $48 \mathrm{~h}$ FSH $(T=48)$ and $6 \mathrm{~h} \mathrm{hCG}(T=48+6)$ compared with pubertal controls $(T=0)$. ( $\mathrm{F}$ and $\mathrm{H})$ Error bars indicate standard errors from three separate experiments. Significant changes in PR levels are marked with one, two and three asterisks for $P<0 \cdot 05, P<0 \cdot 01$, and $P<0 \cdot 001$ respectively. 
by gonadotropins, in which $\mathrm{P}$ released around the time of ovulation may act directly through the ciliated oviduct epithelium to immediate receptivity of the ovulated eggs.

\section{Acknowledgements}

This work was supported by EU project QLRT-2000-00305 (A G B), the Danish Medical Research Science Council 2202-0233 (A G B), the NOVO Foundation (S T C), The Danish Research Science Council (S T C). The authors declare that there is no conflict of interest that would prejudice the impartiality of this scientific work.

\section{References}

Alieva IB, Gorgidze LA, Komarova YA, Chernobelskaya OA \& Vorobjev IA 1999 Experimental model for studying the primary cilia in tissue culture cells. Membrane Cell Biology 12 895-905.

Andrade YN, Fernandes J, Vazquez E, Fernandez-Fernandez JM, Arniges M, Sanchez TM, Villalon M \& Valverde MA 2005 TRPV4 channel is involved in the coupling of fluid viscosity changes to epithelial ciliary activity. Journal of Cell Biology 14 869-874.

Asem EK, Qin W \& Rane SG 2002 Effect of basal lamina of ovarian follicle on $\mathrm{T}$ - and L-type $\mathrm{Ca}(2+)$ currents in differentiated granulosa cells. American Journal of Physiology, Endocrinology and Metabolism 282 E184-E196.

Brenner RM 1969 The biology of oviductal cilia. In The Mammalian Oviduct, edn 1 , pp 203-229. Eds ESE Hafez \& RJ Blandau. Chicago and London: The University of Chicago Press.

Byskov AG 1974 Cell kinetic studies of follicular atresia in the mouse ovary. Journal of Reproduction and Fertility 37 277-285.

Christensen ST, Guerra C, Wada Y, Valentin T, Angeletti RH, Satir P \& Hamasaki T 2001 A regulatory light chain of ciliary outer arm dynein in Tetrahymena thermophila. Journal of Biological Chemistry 276 20048-20054.

Clemm DL, Sherman L, Boonyaratanakornkit V, Schrader WT, Weigel NL \& Edwards DP 2000 Differential hormone-dependent phosphorylation of progesterone receptor $\mathrm{A}$ and $\mathrm{B}$ forms revealed by a phosphoserine sitespecific monoclonal antibody. Molecular Endocrinology 14 52-65.

Conneely OM, Mulac-Jericevic B, Lydon JP \& De Mayo FJ 2001 Reproductive functions of the progesterone receptor isoforms: lessons from knock-out mice. Molecular and Cellular Endocrinology 179 97-103.

Conneely OM, Mulac-Jericevic B \& Lydon JP 2003 Progesterone-dependent regulation of female reproductive activity by two distinct progesterone receptor isoforms. Steroids $\mathbf{6 8} 771-778$.

Denner LA, Schrader WT, O’Malley BW \& Weigel NL 1990 Hormonal regulation and identification of chicken progesterone receptor phosphorylation sites. Journal of Biological Chemistry 265 16548-16555.

Fliegauf M, Olbrich H, Horvath J, Wildhaber JH, Zariwala MA, Kennedy M, Knowles MR \& Omran H 2005 Mislocalization of DNAH5 and DNAH9 in respiratory cells from patients with primary ciliary dyskinesia. American Journal of Respiratory and Critical Care Medicine 171 1343-1349.

Fuentealba B, Nieto M \& Croxatto HB 1987 Ovum transport in pregnant rats is little affected by RU486 and exogenous progesterone as compared to cycling rats. Biology of Reproduction 37 768-774.

Gava N, Clarke CL, Byth K, Arnett-Mansfield RL \& DeFAZIO A 2004 Expression of progesterone receptors A and B in the mouse ovary during the estrous cycle. Endocrinology 45 3487-3494.

Hild-Petito S, Stouffer RL \& Brenner RM 1988 Immunocytochemical localization of estradiol and progesterone receptors in the monkey ovary throughout the menstrual cycle. Endocrinology 123 2896-2905.

Iwai T, Nanbu Y, Iwai M, Taii S, Fujii S \& Mori T 1990 Immunohistochemical localization of oestrogen receptors and progesterone receptors in the human ovary throughout the menstrual cycle. Virchows Archiv. A, Pathological Anatomy and Histopathology 417 369-375.
Iwai T, Fujii S, Nanbu Y, Nonogaki H, Konishi I, Mori T \& Okamura H 1991 Effect of human chorionic gonadotropin on the expression of progesterone receptors and estrogen receptors in rabbit ovarian granulosa cells and the uterus. Endocrinology 129 1840-1848.

Jo M, Komar CM \& Fortune JE 2002 Gonadotropin surge induces two separate increases in messenger RNA for progesterone receptor in bovine preovulatory follicles. Biology of Reproduction 67 1981-1988.

Lange CA 2004 Making sense of cross-talk between steroid hormone receptors and intracellular signaling pathways: who will have the last word? Molecular Endocrinology 18 269-278.

Luconi M, Bonaccorsi L, Bini L, Liberatori S, Pallini V, Forti G \& Baldi E 2002 Characterization of membrane nongenomic receptors for progesterone in human spermatozoa. Steroids 67 505-509.

Lydon JP, DeMayo FJ, Funk CR, Mani SK, Hughes AR, Montgomery CA, Jr., Shyamala G, Conneely OM \& O'Malley BW 1995 Mice lacking progesterone receptor exhibit pleiotropic reproductive abnormalities. Genes \& Development $92266-2278$.

Lyons RA, Djahanbakhch O, Mahmood T, Saridogan E, Sattar S, Sheaff MT, Naftalin AA \& Chenoy R 2002 Fallopian tube ciliary beat frequency in relation to the stage of menstrual cycle and anatomical site. Human Reproduction 17 584-588.

Machelon V, Nome F, Grosse B \& Lieberherr M 1996 Progesterone triggers rapid transmembrane calcium influx and/or calcium mobilization from endoplasmic reticulum, via a pertussis-insensitive G-protein in granulosa cells in relation to luteinization process. Journal of Cellular Biochemistry $\mathbf{6 1}$ 619-628.

Mahmood T, Saridogan E, Smutna S, Habib AM \& Djahanbakhch O 1998 The effect of ovarian steroids on epithelial ciliary beat frequency in the human Fallopian tube. Human Reproduction 13 2991-2994.

Mulac-Jericevic B, Mullinax RA, DeMayo FJ, Lydon JP \& Conneely OM 2000 Subgroup of reproductive functions of progesterone mediated by progesterone receptor-B isoform. Science 289 1751-1754.

Ohta Y, Sato T \& Iguchi T 1993 Immunocytochemical localization of progesterone receptor in the reproductive tract of adult female rats. Biology of Reproduction 48 205-213.

Okada A, Ohta Y, Inoue S, Hiroi H, Muramatsu M \& Iguchi T 2003 Expression of estrogen, progesterone and androgen receptors in the oviduct of developing, cycling and pre-implantation rats. Journal of Molecular Endocrinology 30 301-315.

Orihuela PA \& Croxatto HB 2001 Acceleration of oviductal transport of oocytes induced by estradiol in cycling rats is mediated by nongenomic stimulation of protein phosphorylation in the oviduct. Biology of Reproduction 65 1238-1245.

Orihuela PA, Rios M \& Croxatto HB 2001 Disparate effects of estradiol on egg transport and oviductal protein synthesis in mated and cyclic rats. Biology of Reproduction 65 1232-1237.

Park OK \& Mayo KE 1991 Transient expression of progesterone receptor messenger RNA in ovarian granulosa cells after the preovulatory luteinizing hormone surge. Molecular Endocrinology 5 967-978.

Pedersen T \& Peters H 1968 Proposal for a classification of oocytes and follicles in the mouse ovary. Journal of Reproduction and Fertility 17 555-557.

Peluso JJ 2004 Rapid actions of progesterone on granulosa cells. Steroids $\mathbf{6 9}$ 579-583.

Peluso JJ, Fernandez G, Pappalardo A \& White BA 2001 Characterization of a putative membrane receptor for progesterone in rat granulosa cells. Biology of Reproduction 65 94-101.

Peluso JJ, Bremner T, Fernandez G, Pappalardo A \& White BA 2003 Expression pattern and role of a 60-kilodalton progesterone binding protein in regulating granulosa cell apoptosis: involvement of the mitogen-activated protein kinase cascade. Biology of Reproduction 68 122-128.

Poletti A, Conneely OM, McDonnell DP, Schrader WT, O'Malley BW \& Weigel NL 1993 Chicken progesterone receptor expressed in Sacharomyces cerevisiae is correctly phosphorylated at all four Ser-Pro phosphorylation sites. Biochemistry 32 9563-9569.

Qiu M \& Lange CA 2003 MAP kinases couple multiple functions of human progesterone receptors: degradation, transcriptional synergy, and nuclear association. Journal of Steroid Biochemistry and Molecular Biology $\mathbf{8 5}$ $147-157$. 
Robker RL, Russell DL, Espey LL, Lydon JP, O'Malley BW \& Richards JS 2000 Progesterone-regulated genes in the ovulation process: ADAMTS-1 and cathepsin L proteases. PNAS 97 4689-4694.

Satir P \& Christensen ST 2006. Overview of structure and function of mammalian cilia. Annual Review of Physiology. In press.

Shao R, Markstrom E, Friberg PA, Johansson M \& Billig H 2003 Expression of progesterone receptor (PR) A and B isoforms in mouse granulosa cells: stage-dependent PR-mediated regulation of apoptosis and cell proliferation. Biology of Reproduction 68 914-921.

Sheridan PL, Evans RM \& Horwitz KB 1989 Phosphotryptic peptide analysis of human progesterone receptor. New phosphorylated sites formed in nuclei after hormone treatment. Journal of Biological Chemistry 264 6520-6528.

Slomczynska M, Krok M \& Pierscinski A 2000 Localization of the progesterone receptor in the porcine ovary. Acta Histochemica 102 183-191.

Suzuki T, Sasano H, Kimura N, Tamura M, Fukaya T, Yajima A \& Nagura H 1994 Immunohistochemical distribution of progesterone, androgen and oestrogen receptors in the human ovary during the menstrual cycle: relationship to expression of steroidogenic enzymes. Human Reproduction 9 1589-1595.

Takimoto GS \& Horwitz KB 1993 Progesterone receptor phosphorylation, complexities in defining a functional role. Trends in Endocrinology and Metabolism 4 1-7.

Teilmann SC \& Christensen ST 2005 Ciliary localization of angiopoetin receptors Tie-1 and Tie-2 in the female reproductive organs. Cell Biology International 29 340-346.
Teilmann SC, Byskov AG, Pedersen PA, Wheatley DN, Pazour GJ \& Christensen ST 2005 Localization of transient receptor potential ion channels in primary and motile cilia of the female murine reproductive organs. Molecular Reproduction and Development 71 444-452.

Vanderhyden BC \& Macdonald EA 1998 Mouse oocytes regulate granulosa cell steroidogenesis throughout follicular development. Biology of Reproduction 59 1296-1301.

VanSlyke JK \& Musil LS 2001 Biochemical analysis of connexon assembly. In Connexin Methods and Protocols, edn 1, pp 117-134. Eds R Bruzzone \& C Giaume. Totowa, New Jersey: Humana Press Inc.

Verdugo P $1980 \mathrm{Ca}^{2+}$-dependent hormonal stimulation of ciliary activity. Nature 283 764-765.

Weigel NL 1996 Steroid hormone receptors and their regulation by phosphorylation. Biochemical Journal 319 657-667.

Wessel T, Schuchter U \& Walt H 2004 Ciliary motility in bovine oviducts for sensing rapid non-genomic reactions upon exposure to progesterone. Hormone and Metabolic Research 36 136-141.

Received in final form 22 August 2006

Accepted 23 August 2006

Made available online as an Accepted Preprint 25 September 2006 